\title{
Reduction in Susceptibility to Natural Killer Cell-mediated Lysis of Human FO-1 Melanoma Cells after Induction of HLA Class I Antigen Expression by Transfection with $\mathbf{B}_{\mathbf{2}} \mathbf{m}$ Gene
}

\author{
Michele Maio," Maresa Altomonte, ${ }^{*}$ Revati Tatake," Richard A. Zeff," and Soldano Ferrone* \\ ${ }^{*}$ Division of Experimental Oncology 2 and Immunology Section, Centro di Riferimento Oncologico, Aviano, Italy 33081; ${ }^{\ddagger}$ Department of \\ Microbiology and Immunology, New York Medical College, Valhalla, New York 10595; and Department of Pathology,
}

University of Connecticut, Farmington, Connecticut 06032

\begin{abstract}
Induction of HLA class I antigens on cultured melanoma cells FO-1 after transfection with a human or a mouse $B_{2} m$ gene was associated with a statistically significant reduction in their susceptibility to natural killer (NK) cell-mediated lysis. These results indicate that the structural differences between human and mouse $\beta_{2}-\mu$ do not abolish the ability of the HLA class I molecular complex to modulate NK cell-mediated lysis of melanoma cells FO-1. The role of HLA class I antigens in the phenomenon is corroborated by the ability of anti-HLA class I MAb to enhance, although to a different extent, the susceptibility of transfected FO-1 cells to NK cell-mediated lysis. Gamma interferon (IFN- $\gamma$ ) and tumor necrosis factor- $\alpha$ (TNF- $\alpha$ ) significantly reduced the susceptibility to NK cell-mediated lysis of transfected FO-1 cells. Surprisingly, TNF- $\alpha$ reduced the extent of lysis more than IFN- $\gamma$, although the latter cytokine enhanced HLA class I antigen expression more than the former one. This finding, in conjunction with a reduction in the susceptibility to NK cell-mediated lysis of untransfected FO-1 cells incubated with IFN- $\gamma$ or TNF- $\alpha$, suggests that the two cytokines reduce NK cell-mediated lysis of transfected cells by modulating not only the expression of HLA class I antigens, but also that of other structures. Induction of HLA class I antigens and their modulation with IFN- $\gamma$ did not affect the susceptibility to lymphokine-activated killer (LAK) cell-mediated lysis of transfected FO-1 cells. Characterization of the molecular mechanism(s) underlying abnormalities in HLA class I antigen expression by melanoma cells and of the role of these molecules in the interactions of melanoma cells with various types of effector cells may suggest novel immunotherapeutic approaches to melanoma. (J. Clin. Invest. 1991. 88:282-289.) Key words: IFN $\gamma \cdot \operatorname{monoclonal}$ antibody $\bullet$ LAK cells $\bullet$ TNF- $\alpha$
\end{abstract}

\section{Introduction}

Malignant transformation of melanocytes may be associated with changes in HLA class I antigen expression (for review, see reference 1). These changes may have clinical relevance, be-

Address reprint requests to Soldano Ferrone, M.D., Department of Microbiology and Immunology, Basic Sciences Building, Valhalla, NY 10595.

Received for publication 23 October 1990 and in revised form 14 January 1991.

J. Clin. Invest.

(c) The American Society for Clinical Investigation, Inc.

$0021-9738 / 91 / 107 / 0282 / 08 \$ 2.00$

Volume 88, July 1991, 282-289 cause a statistically significant, although not absolute, association has been found between levels of HLA class I antigen expression in melanoma lesions and clinical course of the disease (2). The mechanism underlying this phenomenon is not known but is of great interest, because its characterization may contribute to our understanding of the role of HLA class I antigens in the biology of melanoma cells and in their interactions with host's immune system. This information may eventually suggest novel therapeutic approaches to melanoma.

Besides their role as restricting elements in the lysis of target cells by cytotoxic T cells (3), HLA class I antigens have been shown to regulate susceptibility to natural killer (NK) ${ }^{1}$ cellmediated lysis of tumor cells in some, although not all, the systems investigated (for review, see reference 4). Scanty and conflicting information is available about the role of HLA class I antigens in NK cell-mediated lysis of melanoma cells. To the best of our knowledge, only Lobo and Spencer (5) and Versteeg et al. (6) have investigated this phenomenon. Lobo and Spencer (5) have reported that cultured melanoma cells SKMEL-1 are particularly resistant to NK cell-mediated lysis; at variance with results obtained with other cell lines, anti-HLA class I MAb did not increase the extent of NK cell-mediated lysis. Versteeg et al. (6) have shown that a spontaneous HLA class I negative variant isolated from the melanoma cell line 518A after long time culturing and the melanoma cells IGR30 with a reduced HLA class I antigen expression after transfection with the c-myc oncogene display an increased susceptibility to NK cell-mediated lysis. Although suggestive, these results do not prove a cause-effect relationship between reduction in HLA class $I$ antigen expression and increased susceptibility to NK cell-mediated lysis of melanoma cells IGR30 and 518A, because prolonged in vitro culturing or transfection with c-myc oncogene may modify the expression of unrelated antigenic structures which modulate susceptibility to NK cell-mediated lysis. Furthermore, the results obtained with most of the tumor systems investigated might not be valid for melanoma cells, because the latter express molecules, such as HLA class II antigens and intercellular adhesion molecule-1 (ICAM-1) $(7,8)$, which may play a role in the interaction of NK cells with target cells (5; Maio, M., and S. Ferrone, unpublished results). Therefore, to eliminate the potential interference of unrelated structures in the analysis of the role of HLA class I

1. Abbreviations used in this paper: ADCC, antibody dependent cell mediated cytotoxicity; $\beta_{2}-\mu, \beta_{2}$-microglobulin; ICAM-1, intercellular adhesion molecule-1; IFN- $\gamma$, gamma interferon; IIF, indirect immunofluorescence; LAK, lymphokine activated killer; NK, natural killer; PBMC, peripheral blood mononuclear cells; TNF- $\alpha$, tumor necrosis factor- $\alpha$. 
antigens in NK cell-mediated lysis of melanoma cells, in the present study, we have characterized the effect of the induction of HLA class I antigens on the susceptibility to NK cell-mediated lysis of melanoma cells FO-1 which do not express HLA class I antigens because of a structural defect in $B_{2} m$ gene ( 9 , 10). Furthermore, because NK cell-mediated lysis of human tumor cells cannot be modulated by $\mathrm{H}-2$ class I heavy chains associated with human $\beta_{2}$-microglobulin $\left(\beta_{2}-\mu\right)(11)$, we have compared the susceptibility to NK cell-mediated lysis of FO-1 cells transfected with a human and a mouse $B_{2} m$ gene to determine the effect of differences in $\beta_{2}-\mu$ structure (12-14) on the lytic phenomenon.

\section{Methods}

Cells. The melanoma cell line Colo 38, the melanoma cell line FO-1 (9), and the cell line FO-1C transfected with a mouse $\mathrm{B}_{2} \mathrm{~m}$ gene (10) were grown in RPMI 1640 medium (Flow Laboratories Inc., McLean, VA) supplemented with $10 \%$ heat-inactivated FCS (Flow Laboratories Inc.) and $2 \mathrm{mM} \mathrm{L}$-glutamine.

Peripheral blood mononuclear cells (PBMC) were separated from heparinized blood of healthy volunteers by Ficoll-Hypaque (Pharmacia Fine Chemicals AB, Uppsala, Sweden) density gradient centrifugation ( $400 \mathrm{~g}$ for $30 \mathrm{~min}$ ). After three washings with HBSS (Flow Laboratories Inc.), they were used either as a source of NK cells or for lymphokine activated killer (LAK) cell generation. The latter were generated by culturing PBMC in the continuous presence of interleukin-2 (IL-2) $(1,000 \mathrm{U} / \mathrm{ml})$ for at least $10 \mathrm{~d}$; half of the medium was changed every 48 $h$ with an equal volume of fresh medium containing IL-2. At the end of the culture more than $95 \%$ of cells were stained by anti-CD3 MAb OKT3 in indirect immunofluorescence (IIF). The functional activity of LAK cell preparations was monitored by testing their ability to lyse the NK cell-resistant cultured melanoma cells Colo 38.

Human $B_{2} m$ gene. Human $\beta_{2}-\mu$ clone $\beta_{2} \mathrm{~m} 13$ in the vector pEMBL9 (14) was purified on a $\mathrm{CsCl}$ gradient cushion and linearized with the restriction enzyme Sal I before transfection.

$M A b$ and conventional antisera. The MAb W6/32, TP25.99.1, and CR 11-115 to distinct monomorphic determinants of HLA class I antigens, the MAb Q6/64 and H2-89-1 to determinants restricted to the gene products of the HLA-B locus, the anti- $\beta_{2}-\mu$ MAb NAMB- 1 , the anti-HLA-DR, DQ, DP MAb Q5/13 and the anti-ICAM-1 MAb CL203.4 were developed and characterized as described elsewhere (1520). Anti-CD3 MAb OKT3 was purchased from Ortho Diagnostic Systems (Milan, Italy). MAb were purified from ascitic fluid by sequential precipitation with caprylic acid and with ammonium sulfate (21). $\mathrm{F}\left(\mathrm{ab}^{\prime}\right)_{2}$ fragments were prepared by incubating purified immunoglobulins $(5 \mathrm{mg} / \mathrm{ml})$ in $100 \mathrm{mM}$ sodium citrate ( $\mathrm{pH} 3.5)$ with $25 \mathrm{mg}$ of pepsin (Sigma Chemical Co., St. Louis, MO) for $18 \mathrm{~h}$ at $37^{\circ} \mathrm{C}$. Digestion was stopped by adding $1 / 10$ volume of $3 \mathrm{M}$ Tris buffer ( $\mathrm{pH} 8.8$ ). Samples were then extensively dialyzed against PBS, $\mathrm{pH}$ 7.2. The purity of MAb and $\mathrm{F}\left(\mathrm{ab} \mathrm{b}_{2}\right)_{2}$ fragment preparations was monitored by SDS-PAGE (22) under reducing and nonreducing conditions. The activity of purified $\mathrm{MAb}$ and $\mathrm{F}\left(\mathrm{ab}^{\prime}\right)_{2}$ fragment preparations was monitored by IIF staining of target cells.

The mixture of mouse IgG, MsIgG, used to monitor nonspecific staining of melanoma cells in IIF was purchased from Coulter Immunology, Hialeah, FL. Rabbit anti-mouse IgG $(\mathrm{H}+\mathrm{L})$ antibodies and fluorescein isothiocyanate conjugated (FITC) $F\left(a b^{\prime}\right)_{2}$ fragments of goat anti-mouse $\operatorname{IgG}(\mathrm{H}+\mathrm{L})$ antibodies were purchased from Jackson Immunoresearch Laboratories, Inc. (West Grove, PA).

Cytokines. Human recombinant gamma interferon (IFN- $\gamma$ ) and IL-2 were obtained from Hoffman-LaRoche Inc., Nutley, NJ; human recombinant TNF- $\alpha$ was obtained from Cetus Corp., Emeryville, CA.

Transfection of FO-1 melanoma cells with human $B_{2} m$ gene. FO-1 melanoma cells were transfected by electroporation as described elsewhere (10). Briefly, cells $\left(5 \times 10^{7}\right)$, linearized human $B_{2}$ m DNA $(100$ $\mu \mathrm{g})$ and Eco RI digested pSV2 neo-DNA (5 $\mu \mathrm{g})$ were mixed in cold sterile PBS $(1 \mathrm{ml})$. Electroporation was performed in a Bethesda Research Laboratories (Gaithersburg, MD) Cell-Porator using an electric pulse of $1 \mathrm{kV}$ at $330 \mu \mathrm{F}$ capacitance. Cells were then resuspended in DMEM supplemented with $10 \%$ FCS at $1 \times 10^{6} / \mathrm{ml}$, seeded in eight $100-\mathrm{mm}$ tissue culture dishes and incubated at $37^{\circ} \mathrm{C}$ in a $5 \% \mathrm{CO}_{2} \mathrm{hu}-$ midified atmosphere. Nonadherent cells were removed after overnight incubation. Cells were fed with DMEM supplemented with $10 \%$ FCS and with G418 sulfate ( $2 \mathrm{mg} / \mathrm{ml}$ ) (Gibco Laboratories, Grand Island, NY). Cells from each plate were grown to confluence. To identify cells transfected with human $B_{2} m$ gene which express HLA class I antigens, cells were sequentially incubated with the anti-human $\beta_{2}-\mu$ MAb NAMB-1 and with FITC conjugated antimouse Ig xenoantibodies and analyzed with a cytofluorograph. FO-1H cells, which were stained by MAb NAMB-1, were sterile sorted, subcloned, and expanded. The expression of HLA class I antigens was corroborated by staining with MAb TP25.99.1 in IIF.

Serological assays. IIF was performed by incubating cells $\left(5 \times 10^{5}\right)$ with an excess of MAb at $4^{\circ} \mathrm{C}$ for $30 \mathrm{~min}$. After three washings with PBS supplemented with $0.5 \%$ BSA and $0.01 \%$ (wt/vol) $\mathrm{NaN}_{3}$ (PBSBSA-AZ) cells were incubated for an additional $30 \mathrm{~min}$ at $4^{\circ} \mathrm{C}$ with FITC-F $\left(\mathrm{ab}^{\prime}\right)_{2}$ fragments of goat anti-mouse IgG $(\mathrm{H}+\mathrm{L})$ antibodies. After three washings with PBS-BSA-AZ, cells were resuspended in PBS-BSA-AZ and analyzed for surface fluorescence utilizing a FACStar flow cytometer (Becton Dickinson Co., Mountain View, CA) equipped with a 9153B computer (Hewlett-Packard Co., Palo Alto, CA). Fluorescence was collected by using a four-decade logarithmic amplifier. Mean fluorescence intensity was converted from a logarithmic to a linear scale using a calibration factor. Viable cells $\left(1 \times 10^{4}\right.$, volume gated) were collected in a list mode fashion for data analysis. The latter was performed with a Consort C30 software (Becton-Dickinson Co.).

Radiolabeling of cells, indirect immunoprecipitation, and SDS$P A G E$. These procedures were performed as described elsewhere (10). Briefly, cells $\left(2 \times 10^{7}\right)$ were labeled with ${ }^{125}$ I (Amersham International, Amersham, UK) utilizing the lactoperoxidase method. They were then incubated for $30 \mathrm{~min}$ at $4^{\circ} \mathrm{C}$ in lysis buffer containing $1 \%$ NP40, 10 $\mathrm{mM}$ Tris- $\mathrm{HCl}$ (pH 8.2), $0.5 \mathrm{M} \mathrm{NaCl}, 1 \mathrm{mM}$ EDTA, $1 \mathrm{mg} / \mathrm{ml} \mathrm{BSA}$, and $1 \mathrm{mM}$ PMSF. The cell extract was incubated for $12 \mathrm{~h}$ with MAb bound to protein A-Sepharose (Pharmacia Fine Chemicals) precoated with rabbit anti-mouse IgG $(H+L)$ antibodies. One-dimensional SDSPAGE was performed on $10 \%$ polyacrylamide slab gels under reducing conditions using the buffer system described by Laemmli (22). Gels were processed for autoradiography using a Kodak XAR-5 film (Eastman Kodak Co., Rochester, NY).

Cytotoxicity assays. All experiments were performed in triplicates in round bottom microtiter plates (Costar, Cambridge, MA). Target cells $\left(2 \times 10^{6}\right)$ were resuspended in $1 \mathrm{ml}$ of RPMI 1640 medium supplemented with $20 \%$ FCS and incubated with $200 \mu \mathrm{Ci}$ of $\mathrm{Na}_{2}{ }^{51} \mathrm{CrO}_{4}$ (Amersham International) for $1 \mathrm{~h}$ at $37^{\circ} \mathrm{C}$ in a $5 \% \mathrm{CO}_{2}$ humidified atmosphere with occasional gentle shaking. After four washings with HBSS, target cells $\left(1 \times 10^{4}\right)$ were incubated for $4 \mathrm{~h}$ at $37^{\circ} \mathrm{C}$ in a final volume of $200 \mu$ l of RPMI 1640 medium containing 10\% FCS with different numbers of effector cells to obtain effector/target cell ratios of $100,50,25,12.5: 1$ and of $20,10,5,2.5: 1$ for NK and LAK cell-mediated lysis, respectively. Then plates were centrifuged and supernatant $(100 \mu \mathrm{l})$ was harvested from each well and counted in a gamma counter. Percent of cytotoxicity was calculated as (experimental ${ }^{51} \mathrm{Cr}$ release-spontaneous ${ }^{51} \mathrm{Cr}$ release/maximum ${ }^{51} \mathrm{Cr}$ release-spontaneous ${ }^{51} \mathrm{Cr}$ release) $\times 100$. Spontaneous release represents the radioactivity released by $1 \times 10^{4}{ }^{\text {s1 }} \mathrm{Cr}$ labeled target cells during a 4-h incubation; maximum release is the radioactivity released by $1 \times 10^{4}$ target cells lysed with NP40. Only experiments with a spontaneous release lower than $15 \%$ were used for the statistical analysis.

Statistical analysis. Data were analyzed with the Student's paired $t$ test utilizing the Statworks statistical package from Cricket Software, Inc. (Philadelphia, PA). Differences with $P$ values of at least 0.05 were considered statistically significant. 


\section{Results}

Expression of HLA class I antigens on FO-I melanoma cells transfected with a mouse or a human $B_{2} m$ gene. The untransfected melanoma cells FO-1, the melanoma cells FO-1C transfected with a mouse $B_{2} \mathrm{~m}$ gene and the melanoma cells FO-1 $\mathrm{H}$ transfected with a human $B_{2} m$ gene were sequentially incubated with the anti-HLA class I MAb TP25.99.1 and with FITC-anti-mouse IgG $(\mathrm{H}+\mathrm{L})$ xenoantibodies and analyzed with a cytofluorograph. No specific staining of FO-1 cells was detected, because the mean fluorescence intensity value of 42 was similar to that obtained with FO-1 cells incubated with the negative control MsIgG. FO-1C and FO-1H melanoma cells were both stained by anti-HLA class I MAb TP25.99.1, with mean fluorescence intensity values of 95 and 156, respectively (Fig. $1 A$ ). The mean fluorescence intensity values of FO-1C and FO- $1 \mathrm{H}$ cells stained with the negative control MsIgG were similar to that obtained with FO-1 melanoma cells. The three melanoma cell lines were brightly stained by anti-HLA class II MAb Q5/13 and by anti-ICAM-1 MAb CL203.4 with mean fluorescence intensity values for the three cell lines of $\sim 140$ and 145 , respectively (data not shown).

The expression of HLA class I antigens on FO-1C and FO$1 \mathrm{H}$ cells was corroborated by the results of SDS-PAGE analysis of antigens immunoprecipitated by the anti-HLA class I MAb TP25.99.1 from ${ }^{125}$ I-labeled FO-1C and FO-1H cells. Two components with the characteristic electrophoretic mobility of the two subunits of HLA class I antigens were found in the immunoprecipitates; the intensity of the components in the immunoprecipitate from FO-1C cells was lower than that of those in the immunoprecipitate from FO-1H cells. Representative results are shown in Fig. 2 which also presents for comparison purposes the SDS-PAGE analysis of antigens immunoprecipitated by anti-ICAM-1 MAb CL203.4 from ${ }^{125}$ I-labeled FO-1,

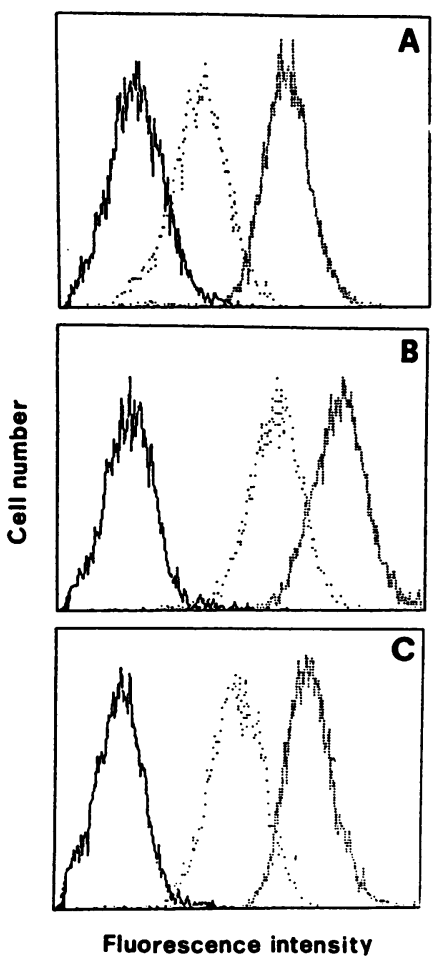

Figure 1. Expression and modulation by cytokines of HLA class I antigens on FO-1, FO$1 \mathrm{C}$, and $\mathrm{FO}-1 \mathrm{H}$ melanoma cells. FO-1 (-), FO-1C $(\cdots)$, and FO-1H $(\cdots \cdots)$ cells were incubated for $42 \mathrm{~h}$ at $37^{\circ} \mathrm{C}$ with IFN- $\gamma(1,000 \mathrm{U} /$ $\mathrm{ml})(B)$ or with TNF- $\alpha(1,000$ $\mathrm{U} / \mathrm{ml})(C)$. Cells incubated under the same experimental conditions, but not exposed to cytokines were used as controls $(A)$. At the end of the incubation, cells were washed and sequentially incubated with anti-HLA class I MAb TP25.99.1 and with FITC conjugated $F\left(a b^{\prime}\right)_{2}$ fragments of goat anti-mouse IgG xenoantibodies. Then cells $\left(1 \times 10^{4}\right.$ volume gated) were analyzed by flow cytometry.
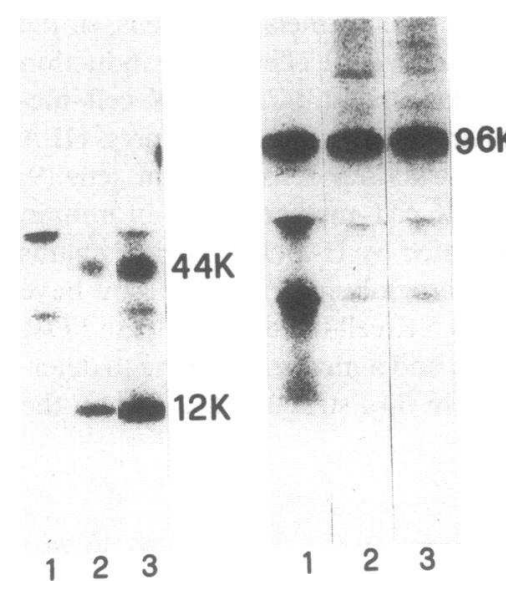

Figure 2. SDS-PAGE analysis of antigens immunoprecipitated by anti-HLA class I MAb TP25.99.1 from FO-1, FO-1C, and FO-1H melanoma cells. FO-1 (lane 1), FO-1C (lane 2), and FO-1H (lane 3) cells were labeled with ${ }^{125}$ I and solubilized with NP40. After indirect immunoprecipitation with MAb TP25.99.1, antigens were eluted from the immunoadsorbent and analyzed by

SDS-PAGE in a $10 \%$ slab gel in the presence of $2 \% \beta$-mercaptoethanol $(l e f t)$. Gels were then processed for autoradiography. Antigens immunoprecipitated by the anti-ICAM-1 MAb CL203.4 from the three melanoma cells lines were used as controls (right).

FO-1C, and FO- $1 \mathrm{H}$ cells. The intensity of ICAM-1 was similar in the immunoprecipitates from the three melanoma cell lines.

Modulation by IFN- $\gamma$ and TNF- $\alpha$ of HLA class I antigen expression by melanoma cells $F O-1, F O-1 C$, and FO- $1 \mathrm{H}$. Incubation for $42 \mathrm{~h}$ with IFN- $\gamma(1,000 \mathrm{U} / \mathrm{ml})($ Fig. $1 B)$ and TNF- $\alpha$ $(1,000 \mathrm{U} / \mathrm{ml})($ Fig. $1 \mathrm{C})$ strongly enhanced the reactivity of FO-1C and FO-1 H melanoma cells with anti-HLA class I MAb TP25.99.1 in IIF. The coefficients of variance $(t)$ obtained with three experiments were $70.2(P=0.0002)$ and $20.3(P=0.002)$ for FO-1C cells treated with IFN- $\gamma$ and TNF- $\alpha$, respectively, and $62.3(P=0.0002)$ and $48.6(P=0.0004)$ for FO-1H cells treated with IFN- $\gamma$ and TNF- $\alpha$, respectively. The increase in HLA class I antigen expression on FO-1C and FO-1H cells induced by IFN- $\gamma$ was more marked than that induced by TNF- $\alpha$. The coefficients of variance $(t)$ obtained with three experiments were $11.2(P=0.007)$ and $20.4(P=0.002)$ for FO-1C and FO-1 $\mathrm{H}$ cells, respectively. The level of HLA class I antigens on FO-1C cells treated with cytokines was significantly lower than that on FO-1H cells treated with cytokines. The coefficients of variance $(t)$ obtained with three experiments were $87.1(P=0.0001)$ and $14.3(P=0.005)$ for IFN- $\gamma$ and TNF- $\alpha$ treated cells, respectively. Neither IFN- $\gamma$ nor TNF- $\alpha$ induced HLA class I antigen expression on FO-1 cells. The coefficients of variance $(t)$ obtained with three experiments were $3.1(P=0.09)$ and $2.5(P=0.12)$ for FO-1 cells treated with IFN- $\gamma$ and TNF- $\alpha$, respectively. A 40-channel increase in the mean fluorescence intensity values was observed when the three melanoma cell lines were stained with the anti-HLA class II MAb Q5/13, after incubation with IFN- $\gamma$ (data not shown). On the other hand, TNF- $\alpha$ did not upregulate the expression of HLA class II antigens. Incubation with IFN- $\gamma$ and TNF- $\alpha$ induced a 40-channel increase in the mean fluorescence intensity values on FO-1, FO-1C, and FO-1 H cells stained with the antiICAM-1 MAb CL203.4 (data not shown).

Susceptibility of FO-1, FO-1C, and FO-1H melanoma cells to NK cell-mediated lysis. FO-1 cells were susceptible to NK cell-mediated lysis. A sixfold variation was observed in the extent of lysis obtained with PBMC isolated from 17 donors, because the ${ }^{51} \mathrm{Cr}$ release ranged between a minimum of $11 \%$ and a maximum of $69 \%$ at the effector/target cell ratio of 100:1. 


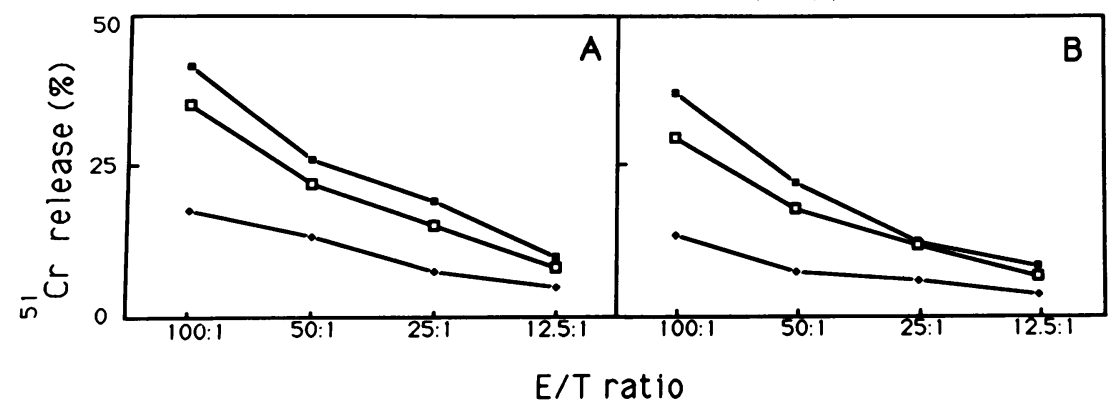

Figure 3. Susceptibility of FO-1, FO-1C, and FO$1 \mathrm{H}$ melanoma cells to NK cell-mediated lysis. FO-1 ( $)$, FO-1C ( $\square$ ), and FO-1H ( $)$ cells were labeled with ${ }^{51} \mathrm{Cr}$ and mixed with PBMC from donor MM (left) and from donor SF (right). At the end of a $4 \mathrm{~h}$ incubation at $37^{\circ} \mathrm{C}$ supernatant was harvested and released radioactivity was measured in a $\gamma$-counter. Data are expressed as percentage of specific ${ }^{51} \mathrm{Cr}$ release.
The mean \pm SD was $37.8 \pm 13.7$. Induction of HLA class I antigen expression on FO-1 cells by transfection with a mouse or a human $\mathrm{B}_{2} \mathrm{~m}$ gene significantly reduced their susceptibility to NK cell-mediated lysis. The mean $\pm \mathrm{SD}$ of ${ }^{51} \mathrm{Cr}$ release from FO-1C and FO-1H cells tested with PBMC from 17 donors at the effector/target cell ratio of $100: 1$ were $30 \pm 15$ with ranges of 4 and 53 and $20 \pm 11$ with ranges of 4 and 51 , respectively. Both values are significantly lower than those obtained with FO-1 cells with $P$ values of 0.00001 and 0.00000004 , respectively. In addition, the ${ }^{51} \mathrm{Cr}$ release from FO-1C cells was significantly higher $(P=0.0006)$ than that from FO-1H cells.

FO-1, FO-1C, and FO-1H cells were also compared in their susceptibility to lysis by PBMC from six of the 17 donors utilizing various effector/target cell ratios, to determine the effect of this variable on the role of HLA class I antigens in NK cell-mediated lysis of FO-1 cells. Results obtained with PBMC from two donors are shown in Fig. 3. As shown in Table I, the level of NK cell-mediated lysis of FO-1 cells was significantly higher than that of FO-1H cells at all the effector/target cell ratios tested and significantly higher than that of FO-1C cells only at the effector/target cell ratios of 100:1 and 50:1. Furthermore, the extent of NK cell-mediated lysis of FO-1 H cells was signifcantly lower than that of FO-1C cells at all the effector/target cell ratios tested, but that of 12.5:1.

Table I. Effect of HLA Class I Antigen Induction on the Susceptibility of Cultured Human Melanoma Cells F0-I to NK Cell-Mediated Lysis

\begin{tabular}{lllcc}
\hline & \multicolumn{4}{c}{ Effector/target cell ratio } \\
\cline { 2 - 5 } Cells & $100: 1$ & $50: 1$ & $25: 1$ & $12.5: 1$ \\
\hline F0-1 & $39 \pm 7^{*}$ & $25 \pm 9$ & $15 \pm 7$ & $10 \pm 5$ \\
F0-1C & $31 \pm 3$ & $20 \pm 9$ & $13 \pm 7$ & $7 \pm 5$ \\
$P<$ & $0.005^{\ddagger}$ & 0.006 & $\mathrm{NS}^{\S}$ & $\mathrm{NS}$ \\
Fo-1 & $39 \pm 7$ & $25 \pm 9$ & $15 \pm 7$ & $10 \pm 5$ \\
F0-1H & $21 \pm 7$ & $14 \pm 7$ & $9 \pm 5$ & $6 \pm 3$ \\
$P<$ & 0.001 & 0.001 & 0.004 & 0.03 \\
F0-1C & $31 \pm 8$ & $20 \pm 9$ & $13 \pm 7$ & $7 \pm 5$ \\
F0-1H & $21 \pm 7$ & $14 \pm 7$ & $9 \pm 5$ & $6 \pm 3$ \\
$P<$ & 0.007 & 0.009 & 0.02 & NS \\
& & & & \\
\hline
\end{tabular}

F0-1, F0-1C, and F0-1 $\mathrm{H}$ cells were labeled with ${ }^{51} \mathrm{Cr}$ and incubated at $37^{\circ} \mathrm{C}$ for $4 \mathrm{~h}$ with PBMC. The supernatant was then harvested and released radioactivity was measured in a $\gamma$-counter. Data are expressed as percentage of specific ${ }^{51} \mathrm{Cr}$ release. * Mean $\pm \mathrm{SD}$ of percentage of specific ${ }^{51} \mathrm{Cr}$ release obtained in at least six experiments. ${ }^{\ddagger}$ Data were analyzed utilizing a paired $t$ test. ${ }^{8} P>0.05$.
Effect of anti-HLA class I MAb on NK cell-mediated lysis of FO-1, FO-1C, and FO-1 H melanoma cells. To corroborate the role of HLA class I antigens in the reduction of NK cell-mediated lysis of FO-1C and FO-1H cells and to investigate the role of distinct determinants of HLA class I antigens in this phenomenon, the effect of MAb to five distinct determinants of HLA class I antigens on the NK cell-mediated lysis of FO$1 \mathrm{C}$ and FO-1H cells was analyzed. Incubation for $30 \mathrm{~min}$ of melanoma cells with MAb TP25.99.1 and W6/32 to monomorphic determinants of HLA-A, B, and C antigens and with anti-HLA-B antigen MAb H2-89-1 and Q6/64 markedly enhanced the NK cell-mediated lysis of FO-1C and FO-1H cells. On the other hand, the MAb CR11-115 to a monomorphic determinant of HLA-A, B, and C antigens had no detectable effect on the extent of lysis. Furthermore, the five anti-HLA class I MAb did not affect the extent of NK cell-mediated lysis of FO- 1 cells. Results of a representative experiment are shown in Table II. Each MAb has been tested at least twice with reproducible results. Furthermore, similar results were obtained

Table II. Differential Effect of MAb to Distinct Determinants of HLA Class I Antigens on the Susceptibility of F0-1C and F0-1H Melanoma Cells to NK Cell-mediated Lysis

\begin{tabular}{|c|c|c|c|c|c|c|c|}
\hline & & $\mathrm{FO}-1$ & & F0-1C & & $\mathrm{FO}-1 \mathrm{H}$ & \\
\hline MAb & & ${ }^{51} \mathrm{Cr}$ release & $\%$ & ${ }^{s 1} \mathrm{Cr}$ release & $\%$ & ${ }^{51} \mathrm{Cr}$ release & $\%$ \\
\hline None & & 36.5 & - & 24.0 & - & 15.8 & - \\
\hline H2-89-1 & (IgG) & $40.8^{*}$ & $11^{\ddagger}$ & 38.7 & 61 & 38.6 & 144 \\
\hline & $\mathrm{F}\left(\mathrm{ab}^{\prime}\right)_{2}$ & 37.1 & 2 & 36.3 & 51 & 39.4 & 149 \\
\hline Q6/64 & (IgG) & 39.5 & 8 & 33.2 & 38 & 31.7 & 100 \\
\hline CR11-115 & (IgG) & 38.5 & 5 & 26.1 & 8 & 16.1 & 2 \\
\hline TP25.99.1 & $(\mathrm{IgG})$ & 38.5 & 5 & 33.8 & 40 & 25.1 & 63 \\
\hline & $F\left(a b^{\prime}\right)_{2}$ & 39.0 & 7 & 31.6 & 32 & 23.8 & 51 \\
\hline W6/32 & (IgG) & 34.4 & - & 27.6 & 15 & 26.7 & 68 \\
\hline
\end{tabular}

F0-1, F0-1C, F0-1H cells were incubated for $30 \mathrm{~min}$ at room temperature with MAb H2-89-1 and Q6/64 to determinants restricted to HLA-B antigens and with MAb CR11-115, TP25.99.1, and W6/32 to monomorphic determinants of HLA class I antigens (final concentration, $20 \mu \mathrm{g} / \mathrm{ml}$ ). Cells incubated under the same experimental conditions with mouse immunoglobulins were used as controls. At the end of the incubation, cells were washed, labeled with ${ }^{51} \mathrm{Cr}$, and incubated at $37^{\circ} \mathrm{C}$ for $4 \mathrm{~h}$ with PBMC from donor MM at the effector/ target cell ratio of 100:1. The supernatant was then harvested and released radioactivity was measured in a $\gamma$-counter. Data are expressed as percentage of specific ${ }^{51} \mathrm{Cr}$ release. * Percentage of specific ${ }^{51} \mathrm{Cr}$ release. ${ }^{\ddagger}$ Percentage increase of specific ${ }^{51} \mathrm{Cr}$ release as compared with ${ }^{51} \mathrm{Cr}$ release in the presence of mouse immunoglobulins. 


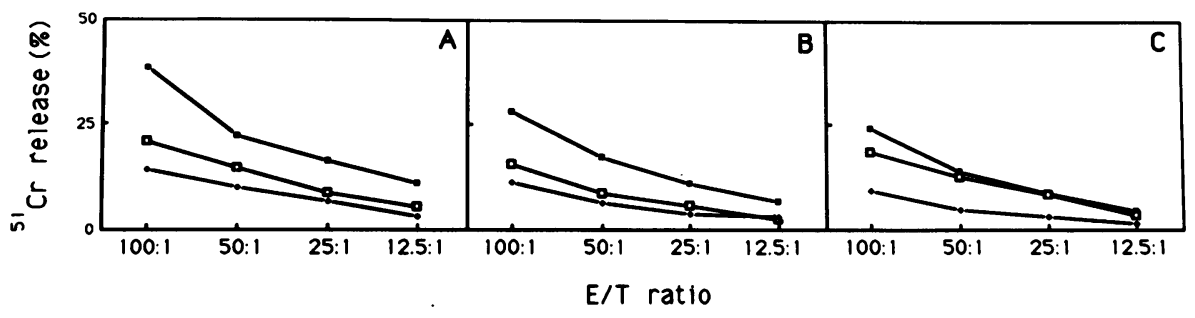

Figure 4. Effect of IFN- $\gamma$ and TNF- $\alpha$ on the susceptibility of FO-1, FO-1C, and FO$1 \mathrm{H}$ melanoma cells to NK cell-mediated lysis. FO-1 (ם), FO-1C (口), and FO-1H (•) cells were incubated for $42 \mathrm{~h}$ at $37^{\circ} \mathrm{C}$ with IFN- $\gamma(1,000 \mathrm{U} / \mathrm{ml})(B)$ or with TNF- $\alpha$ $(1,000 \mathrm{U} / \mathrm{ml})(C)$. Cells incubated under the same experimental conditions, but not exposed to cytokines were used as controls $(A)$. At the end of the incubation, cells were washed, labeled with ${ }^{51} \mathrm{Cr}$, and incubated at $37^{\circ} \mathrm{C}$ for $4 \mathrm{~h}$ with PBMC from donor MA. The supernatant was then harvested and released radioactivity was measured in a $\gamma$-counter. Data are expressed as percentage of specific ${ }^{51} \mathrm{Cr}$ release.

when MAb were added to the mixture of melanoma cells and PBMC. The anti-HLA class I MAb did not enhance NK cellmediated lysis of FO-1C and FO-1H cells by mediating an antibody-dependent cell mediated cytotoxicity (ADCC) phenomenon, because their $F\left(a b^{\prime}\right)_{2}$ fragments were as effective as the whole IgG (Table II). No marked difference was found between FO- $1 \mathrm{C}$ and FO- $1 \mathrm{H}$ cells incubated with anti-HLA class I MAb in terms of extent of NK cell-mediated lysis. On the other hand, the percentage of increase of NK cell-mediated lysis of FO-1H cells induced by MAb H2-89-1, Q6/64, TP25.99.1, and W6/32 was greater than that of FO-1C cells. The anti-HLA class I MAb differed in their ability to enhance the NK cell-mediated lysis of FO-1C and FO-1 H cells. The effect of the antiHLA class I MAb tested did not correlate with the level of expression of the corresponding determinants: the MAb $\mathrm{H} 2$ 89-1 which recognizes a determinant restricted to HLA-B antigens displayed a higher enhancing effect than MAb TP25.99.1 and $\mathrm{W} 6 / 32$ which recognize determinants expressed on the gene products of HLA-A, B, and C loci (Table II).

Effect of IFN- $\gamma$ and TNF- $\alpha$ treatment on the susceptibility of FO-1, FO-1C, and FO-1H melanoma cells to NK cell-mediated lysis. To determine whether cytokines modulate NK cell-mediated lysis of melanoma cells and whether the effect requires HLA class I antigen expression by target cells, FO-1, FO- $1 \mathrm{C}$, and FO-1H cells were first incubated with IFN- $\gamma$ $(1,000 \mathrm{U} / \mathrm{ml})$ or TNF- $\alpha(1,000 \mathrm{U} / \mathrm{ml})$ for $42 \mathrm{~h}$ and then tested for susceptibility to NK cell-mediated lysis. Results of an experiment with PBMC from one donor are shown in Fig. 4. A summary of the results obtained with PBMC from six donors is presented in Fig. 5. IFN- $\gamma$-treated FO- $1 \mathrm{C}$ and FO- $1 \mathrm{H}$ cells displayed a significantly lower susceptibility to NK cell-mediated lysis than their untreated counterparts, with $P$ values of 0.01 and 0.04 , respectively. IFN- $\gamma$-treated FO- 1 cells were also less susceptible to NK cell-mediated lysis than their untreated counterparts; the difference, however, did not reach the level of statistical significance. Furthermore, a comparison of the susceptibility to NK cell-mediated lysis of IFN- $\gamma$-treated untransfected and $\mathrm{B}_{2} \mathrm{~m}$-transfected FO-1 cells showed that at the effector/target cell ratio of 50:1 the extent of lysis of FO-1H cells was significantly lower than that of untransfected FO-1 cells $(P$ $=0.001$ ), but not significantly different from that of FO-1C cells. The latter displayed a significantly $(P=0.01)$ lower susceptibility to NK cell-mediated lysis than untransfected FO-1 cells. At the effector/target cell ratio of $25: 1$, only the difference between the NK cell-mediated lysis of FO-1H and FO-1 cells remained statistically significant with a $P$ value of 0.01 .

Incubation with TNF- $\alpha(1,000 \mathrm{U} / \mathrm{ml})$ for $42 \mathrm{~h}$ induced changes in the susceptibility to NK cell-mediated lysis of FO$1 \mathrm{C}, \mathrm{FO}-1 \mathrm{H}$, and untransfected FO-1 cells similar to those in- duced by IFN- $\gamma$. The reduction in the susceptibility to NK cell-mediated lysis of FO-1 and FO-1H cells induced by TNF$\alpha$ was more marked than that induced by IFN- $\gamma$. However, the difference between TNF- $\alpha$-treated FO- 1 and FO- $1 \mathrm{H}$ cells and their IFN- $\gamma$-treated counterparts did not reach the level of statistical significance.

Lack of effect of HLA class I antigen induction on the susceptibility of FO-1 melanoma cells to LAK cell-mediated lysis. FO-1 cells were highly susceptible to lysis by LAK cells. Induction of HLA class I antigen expression after transfection of FO-1 cells with a human or a mouse $B_{2} m$ gene reduced their susceptibility to LAK cell mediated lysis. Results of an experiment with LAK cells from one donor are shown in Fig. $6 \mathrm{~A}$. The difference, however, in the extent of lysis of FO-1, FO-1C, and FO-1 $\mathrm{H}$ cells by LAK cells generated from five donors did not reach the level of statistical significance. Furthermore, incubation of FO-1, FO- 1 C, and FO- $1 \mathrm{H}$ cells with IFN- $\gamma(1,000$ $\mathrm{U} / \mathrm{ml}$ ) for $42 \mathrm{~h}$ had only a slight effect on the susceptibility of the three cell lines to LAK cell-mediated lysis. Results of an experiment with LAK cells from one donor are shown in Fig. $6 B$.

\section{Discussion}

Transfection with a human or a mouse $B_{2} m$ gene induced HLA class I antigen expression on cultured human melanoma cells FO-1 which lack these antigens (9) because of a $B_{2} m$ gene de-

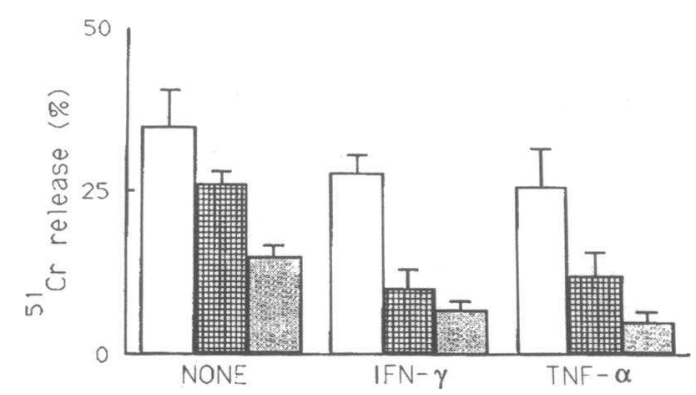

Figure 5. Effect of IFN- $\gamma$ and TNF- $\alpha$ on the susceptibility of FO-1, FO-1C, and FO-1H melanoma cells to NK cell-mediated lysis. FO-1 (ㅁ), FO-1C (田), and FO-1 $\mathrm{H}$ (田) cells were incubated for $42 \mathrm{~h}$ at $37^{\circ} \mathrm{C}$ with IFN- $\gamma(1,000 \mathrm{U} / \mathrm{ml})$ or with TNF- $\alpha(1,000 \mathrm{U} / \mathrm{ml})$. Cells incubated under the same experimental conditions, but not exposed to cytokines were used as controls. At the end of the incubation, cells were washed, labeled with ${ }^{51} \mathrm{Cr}$, and incubated at $37^{\circ} \mathrm{C}$ for $4 \mathrm{~h}$ with PBMC from six donors of the effector/target cell ratio of 50:1. The supernatant was then harvested and released radioactivity was measured in a $\gamma$-counter. Data are expressed as the mean \pm SD of the percentage of specific ${ }^{51} \mathrm{Cr}$ release obtained in six experiments. 


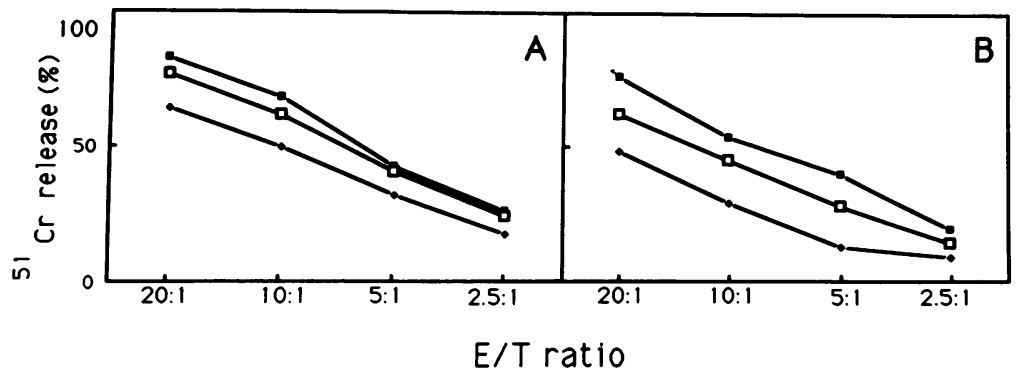

Figure 6. Effect of IFN- $\gamma$ on the susceptibility of FO-1, FO-1C, and FO-1H melanoma cells to LAK cell-mediated lysis. FO-1 ( $($ ), FO-1C ( $\square$ ), and FO-1H ( $\bullet$ ) cells were incubated for $42 \mathrm{~h}$ at $37^{\circ} \mathrm{C}$ with IFN- $\gamma(1,000 \mathrm{U} / \mathrm{ml})$ $(B)$. Cells incubated under the same experimental conditions, but not exposed to IFN- $\gamma$ were used as controls $(A)$. At the end of the incubation, cells were washed, labeled with ${ }^{51} \mathrm{Cr}$, and incubated at $37^{\circ} \mathrm{C}$ for $4 \mathrm{~h}$ with LAK cells from donor CY. Then the supernatant was harvested and released radioactivity was measured in a $\gamma$-counter. Data are expressed as percentage of specific ${ }^{51} \mathrm{Cr}$ release. fect (10). The level of HLA class I antigens on FO-1 cells transfected with a mouse $B_{2} m$ gene is lower than that on cells transfected with a human $B_{2} m$ gene. Although the number of copies of human and mouse $\mathrm{B}_{2} \mathrm{~m}$ gene transfected into FO-1 cells is not known, the difference in HLA class I antigen expression is not likely to result from a limiting amount of $\beta_{2}-\mu$ mRNA, because the intensity of the component hybridizing with $\beta_{2}-\mu$ probe in Northern blot experiments is similar in cells transfected with the human and mouse $B_{2} m$ gene (Tatake, R., $S$. Ferrone, and R. A. Zeff, unpublished results). On the other hand, the different HLA class I antigen expression may reflect the higher efficiency in the association of HLA class I heavy chains with human than with mouse $\beta_{2}-\mu(23,24)$. Assembly of the two subunits and transport and insertion into the cell membrane of the HLA class I molecular complex are enhanced by IFN- $\gamma$ and to a lower extent by TNF- $\alpha$. A similar observation has been made in two mouse tumor cell lines (25).

The susceptibility of FO-1 cells to NK cell-mediated lysis was significantly reduced after induction of HLA class I antigen expression by transfection with a human or a mouse $B_{2} m$ gene. The significant reduction in the susceptibility to NK cellmediated lysis of FO-1 cells transfected with a mouse $\mathrm{B}_{2} \mathrm{~m}$ gene is noteworthy, because it shows that the structural differences between human and mouse $\beta_{2}-\mu(12-14)$ do not abolish the ability of the HLA class I molecular complex to reduce the susceptibility to NK cell-mediated lysis of FO-1 melanoma cells. On the other hand, replacement of HLA class I heavy chain with the mouse counterpart is associated with the loss of the ability to modulate NK cell-mediated lysis of a cultured lymphoid cell line (11). These results altogether strongly suggest that the heavy chain of the HLA class I molecular complex plays the major role in the modulation of NK cell-mediated lysis of tumor cells.

The increase induced by anti-HLA class I MAb in NK cellmediated lysis of FO-1C and FO-1 H cells corroborates the role of HLA class I antigens in this phenomenon. Furthermore, the lack of effect of anti-HLA class I MAb on NK cell-mediated lysis of untransfected FO-1 cells indicates that they modulate the extent of lysis by interacting with the target cells and not with the effector cells. The latter conclusion is in agreement with data by Sturmhofel and Hammerling (26). An anti-H-2 class I MAb did not affect the NK cell-mediated lysis of a variant of mouse thymoma EL4 cells which does not express H-2 class I antigens, but enhanced that of the cells which had acquired H-2 class I antigens after transfection with a mouse $\mathrm{B}_{2} \mathrm{~m}$ gene.

The differential susceptibility to NK cell-mediated lysis of FO-1C and FO-1 $\mathrm{H}$ cells suggests a relationship between extent of NK cell-mediated lysis of tumor cells and their level of HLA class I antigen expression. This possibility is supported by the inverse relationship between the susceptibility to NK cell-mediated lysis and the level of expression of major histocompatibility complex (MHC) class I antigens by various human and mouse tumor cell lines $(11,26-31)$. The latter include clones of cell lines with spontaneous different expression of MHC class I antigens, clones which acquire different levels of MHC class I antigens after correction of the structural abnormality of the defective gene and cells with differential loss of MHC class I antigens after mutagenesis and selection with antibodies and complement. However, in our system, we cannot exclude the role of antigenic differences of the HLA class I molecular complex expressed by FO-1C and FO-1H cells, because association with xenogeneic $\beta_{2}-\mu$ may change the antigenic profile of HLA class I heavy chain (32) and FO-1C cells differ from FO-1H cells in the reactivity pattern with a panel of anti-HLA class I MAb (Tatake, R., S. Ferrone, and R. A. Zeff, unpublished results). Nevertheless, the role of quantitative differences in the level of HLA class I antigen expression by FO-1C and FO-1H cells is suggested by the additional reduction in their susceptibility to NK cell-mediated lysis associated with the enhancement of HLA class I antigen expression by IFN- $\gamma$ and TNF- $\alpha$. The effect was more marked on FO-1C cells than on FO-1H cells, because the difference in the susceptibility to NK cell-mediated lysis between these two types of targets was lost after incubation with the cytokines. The latter results support Storkus et al.'s (33) suggestion that the extent of NK cell-mediated lysis is correlated to HLA class I antigen expression only within certain ranges of expression. No significant change is detected in the extent of NK cell-mediated lysis, when HLA class I antigen expression is below a threshold level or above a plateau level.

The increase in NK cell-mediated lysis of melanoma cells induced by anti-HLA class I MAb parallels similar results obtained with human $T$ cell lymphomas, breast carcinoma cells (34) and lung small cell carcinomas (5) and with mouse thymoma cells (26). On the other hand, these results are at variance with the lack of effect of anti-MHC class I antibodies on the NK cell-mediated lysis of human (5) and mouse (35) melanoma cells and of human lymphoblastoid cells (27). Furthermore, our results differ from those in the literature in two aspects; in Lobo and Spencer's (5) experiments, only target cells which do not express HLA class II antigens were susceptible to increase in NK cell-mediated lysis by anti-HLA class I antibodies, whereas in our studies, the phenomenon was observed with a melanoma cell line which expresses HLA class II antigens. Whether this discrepancy reflects technical reasons or the differential expression by the target cells used of adhesion molecules like ICAM-1, which play a role in the interaction of target cells with effector cells (Maio, M., and S. Ferrone, unpublished results), remains to be determined. Furthermore, in 
Jabrane-Ferrat et al.'s experiments (34), the whole IgG of the anti-HLA class I MAb tested enhanced the extent of NK cellmediated lysis, whereas the $F\left(a b^{\prime}\right)_{2}$ fragments did not, therefore suggesting that the increase mediated by anti-HLA class I MAb may reflect an ADCC phenomenon. On the other hand, in our experiments, the whole IgG of anti-HLA class I MAb were as effective as $F\left(a b^{\prime}\right)_{2}$ fragments in enhancing NK cell-mediated lysis of melanoma cells FO-1C and FO-1H. Whether the conflicting results reflect differences in the characteristics of the MAb tested and/or in the antigenic profile of the cells used as targets in the two studies remains to be determined. In agreement with the results obtained by Lobo and Spencer (5) who utilized cultured lymphoid cells as targets, we have found a differential effect of MAb to distinct monomorphic determinants of HLA class I antigens on NK cell-mediated lysis of melanoma cells. This finding does not appear to correlate with the affinity constants of the MAb tested and/or with the level of expression of the corresponding determinants on target cells. On the other hand, the mapping to the $\alpha 1 / 2$ domains of HLA class I heavy chains of the epitope(s) required for protection against NK cell-mediated lysis (33) suggests that the differential effect of the anti-HLA class I MAb tested may reflect differences in the distribution of the corresponding determinants on the three domains of HLA class I heavy chains. In this regard, testing with mouse cells transfected with $\mathrm{H} 2 / \mathrm{HLA}$ class I hybrid genes has shown that the determinant recognized by MAb $\mathrm{H} 2-89-1$ with the strongest modulatory effect is expressed on the $\alpha 2$ domain, whereas that recognized by MAb CR 11-115 with no detectable effect is expressed on the $\alpha 2$ and $\alpha 3$ domain (Takiguchi, M., and S. Ferrone, unpublished results).

The results with IFN- $\gamma$ or TNF- $\alpha$-treated melanoma cells deserve some comments, because they may suggest some explanations for the conflicting information about the effect of cytokines on NK cell-mediated lysis of tumor cells. Although not statistically significant, the reduction in the susceptibility to NK cell-mediated lysis of FO-1 cells after incubation with IFN- $\gamma$ or TNF- $\alpha$ suggests that the two cytokines modulate the expression not only of HLA class I antigens but also of other structures which are involved in the phenomenon. The role of the latter structures which will be referred to as non-HLA-NK cytolysis related structures is also suggested by the more marked effect of TNF- $\alpha$ than of IFN- $\gamma$ on NK cell-mediated lysis of melanoma cells $\mathrm{FO}-1 \mathrm{H}$, although the latter cytokine enhances HLA class I antigen expression more than the former one. In addition, these results suggest that the non-HLA-NK cytolysis related structures are more susceptible to modulation by TNF- $\alpha$ than by IFN- $\gamma$. A precedent for the latter possibility is represented by the higher susceptibility of ICAM-1 to modulation by TNF- $\alpha$ than by IFN- $\gamma(36)$. The differential expression of the non-HLA-NK cytolysis related structures and of HLA class I antigens may account for the conflicting data about the effect of IFN- $\gamma$ on NK cell-mediated lysis of various types of human tumor cells (37-44). Furthermore, the modulation of the non-HLA-NK cytolysis-related structures may account for the reduction in the susceptibility to NK cell-mediated lysis of tumor cells after incubation with IFN- $\gamma$, but not after transfection with HLA class I genes, although the two approaches induce similar levels of HLA class I antigens (43, 45). The reduction in the susceptibility to NK cell-mediated lysis of FO- 1 cells after incubation with IFN- $\gamma$ is similar to the slight decrease in NK cell-mediated lysis of a cultured B lymphoblastoid cell line after incubation with IFN- $\gamma$, although the low HLA class I antigen expression did not change (37). These results are at variance with the lack of effect of IFN- $\gamma$ on the NK cell-mediated lysis of variants of the mouse cell lines EL4 (26) and YAC (46), both of which do not express H-2 class I antigens. If not caused by technical factors, the different results may reflect differential expression by various tumor cell lines of non-MHC-NK cytolysis-related structures. Furthermore, the lack of statistical significance in the difference of NK cellmediated lysis between control and IFN- $\gamma$ treated FO- 1 cells suggests that the modulation by IFN- $\gamma$ of the non-HLA-NK cytolysis-related structures is not sufficient to change the susceptibility of target cells to NK cell-mediated lysis.

The lack of effect of HLA class I antigen expression and modulation by IFN- $\gamma$ on the susceptibility of melanoma cells FO-1 to LAK cell-mediated lysis parallels similar findings with a cultured B lymphoid cell line which acquires HLA class I antigens after transfection with HLA class I genes (11). These findings are in conflict with results obtained with other cell lines. Quillet et al. (41) have described a reduction in susceptibility to LAK cell-mediated lysis of cultured B lymphoid cells Daudi which have acquired HLA class I antigens after transfection with a human $B_{2} m$ gene. Furthermore, Ohlen et al. (30) have reported an inverse relationship between the level of HLA class I antigen expression by HLA loss variants of a cultured B lymphoid cell line and their susceptibility to LAK cell-mediated lysis. Lastly, Jabrane-Ferrat et al. (34) utilizing human breast carcinoma cells and Tsai et al. (47) utilizing mouse lymphoma and melanoma cells have shown that enhancement of MHC class I antigen expression on target cells incubated with IFN- $\gamma$ reduces their susceptibility to LAK cell-mediated lysis.

The results we have shown indicate a differential role of HLA class I antigens in the lysis of melanoma cells FO-1 by various types of effector cells. This information in conjunction with the characterization of the molecular basis of abnormalities in HLA class I antigen expression by melanoma cells may suggest novel immunotherapeutic approaches to melanoma.

\section{Acknowledgements}

The authors thank Dr. H. L. Ploegh, Department of Immunology, The Netherlands Cancer Institute, Amsterdam, The Netherlands, for providing a genomic human $\beta_{2}-\mu$ clone and acknowledge the excellent secretarial assistance of Mrs. Edwina L. Jones, Mrs. Harriett V. Harrison, Mrs. Donna D. James, and Miss Gail D. Price.

This work was supported by the Associazione Italiana per la Ricerca sul Cancro, by the Publich Health Service grant CA37959 and CA39559 awarded by the National Cancer Institute, Department of Health and Human Services, by grants IM-500 and IM- 554 awarded by the American Cancer Society, and by grant CT-219-8809 awarded by the American Heart Association. M. Maio was supported by a fellowship from an Italia-United States exchange program awarded by the Consiglio Nazionale delle Ricerche and National Institutes of Health. R. A. Zeff is an Established Investigator of the American Heart Association.

\section{References}

1. Ruiter, D. J., V. Mattijssen, E.-B. Broecker, and S. Ferrone. 1991. MHC antigens in human melanomas. Semin. Cancer Biol. In press.

2. van Duinen, S. G., D. J. Ruiter, E. B. Broecker, E. A. van der Velde, C Sorg, K. Welvaart, and S. Ferrone. 1988. Level of HLA antigens in locoregional metastases and clinical course of the disease in patients with melanoma. Cancer Res. 48:1019-1025. 
3. McMichael, A. J. 1980. HLA restriction of human cytotoxic T cells. Springer Semin. Immunopathol. 3:3-22.

4. Ljunggren, H.-G., and K. Karre. 1990. In search of the 'missing self': MHC molecules and NK cell recognition. Immunol. Today. 11:237-244.

5. Lobo, P. I., and C. E. Spencer. 1989. Use of anti-HLA antibodies to mask major histocompatibility complex gene products on tumor cells can enhance susceptibility of these cells to lysis by natural killer cells. J. Clin. Invest. 83:278287.

6. Versteeg, R., L. T. C. Peltenburg, A. C. Plomp, and P. I. Schrier. 1989. High expression of the $c-m y c$ oncogene renders melanoma cells prone to lysis by natural killer cells. J. Immunol. 143:4331-4337.

7. Wilson, B. S., F. Indiveri, M. A. Pellegrino, and S. Ferrone. 1979. DR (la-like) antigens on human melanoma cells. Serological detection and immunochemical characterization. J. Exp. Med. 149:658-668.

8. Maio, M., B. Gulwani, J. A. Langer, R. S. Kerbel, G. J. Duigou, P. B. Fisher, and S. Ferrone. 1989. Modulation by interferons of HLA antigen, high-molecular-weight melanoma-associated antigen, and intercellular adhesion molecule 1 expression by cultured melanoma cells with different metastatic potential. Cancer Res. 49:2980-2987.

9. Guarini, L., M. Temponi, G. M. Edwalds, J. R. Vita, P. B. Fisher, and S. Ferrone. 1989. In vitro differentiation and antigenic changes in human melanoma cell lines. Cancer Immunol. Immunother. 30:262-276.

10. D'Urso, C. M., Z. Wang, Y. Cao, R. Tatake, R. A. Zeff, and S. Ferrone 1991. Lack of HLA Class I antigen expression by cultured melanoma cells FOdue to a defect in $\mathrm{B}_{2} \mathrm{~m}$ gene expression. J. Clin. Invest. 87:284-292.

11. Storkus, W. J., J. Alexander, J. A. Payne, J. R. Dawson, and P. Cresswell. 1989. Reversal of natural killing susceptibility in target cells expressing transfected class I HLA genes. Proc. Natl. Acad. Sci. USA. 86:2361-2364.

12. Suggs, S. V., R. B. Wallace, T. Hirose, E. H. Kawashima, and K. Itakura 1981. Use of synthetic oligonucleotides as hybridization probes: isolation of cloned cDNA sequences for human $\beta_{2}$-microglobulin. Proc. Natl. Acad. Sci. USA. 78:6613-6617.

13. Parnes, J. R., and J. G. Seidman. 1982. Structure of wild-type and mutant mouse $\beta_{2}$-microglobulin genes. Cell. 29:661-669.

14. Gussow, D., R. Rein, I. Ginjaar, F. Hochstenbach, G. Seemann, A. Kottman, and $H$. L. Ploegh. 1987. The human $\beta_{2}$-microglobulin gene. Primary structure and definition of the transcriptional unit. J. Immunol. 139:3132-3138.

15. Barnstable, C. J., W. F. Bodmer, G. Brown, G. Galfre, C. Milstein, A. F. Williams, and A. Ziegler. 1978. Production of monoclonal antibodies to group A erythrocytes, HLA and other human cell surface antigens: new tools for genetic analysis. Cell. 14:9-20.

16. Turco, M. C., M. De Felice, L. Corbo, G. Morrone, R. Mertelsmann, S. Ferrone, and S. Venuta. 1985. Regulatory role of monomorphic determinant of HLA class I antigens in T cell proliferation. J. Immunol. 135:2268-2273.

17. Quaranta, V., M. A. Pellegrino, and S. Ferrone. 1981. The monoclonal xenoantibody Q6/64 recognizes a determinant expressed by certain gene products of the A and B loci of the HLA region. Immunogenetics. 14:403-413.

18. Pellegrino, M. A., A.-K. Ng, C. Russo, and S. Ferrone. 1982. Heterogeneous distribution of the determinants defined by monoclonal antibodies on HLA-A and B antigens bearing molecules. Transplantation. 34:18-24.

19. Quaranta, V., L. E. Walker, M. A. Pellegrino, and S. Ferrone. 1980. Purification of immunologically functional subsets of human la-like antigens on a monoclonal antibody (Q5/13) immunoadsorbent. J. Immunol. 125:14211425 .

20. Matsui, M., M. Temponi, and S. Ferrone. 1987. Characterization of a monoclonal antibody-defined human melanoma-associated antigen susceptible to induction by immune interferon. J. Immunol. 139:2088-2094.

21. Temponi, M., T. Kageshita, F. Perosa, R. Ono, H. Okada, and S. Ferrone. 1989. Purification of murine IgG monoclonal antibodies by precipitation with caprylic acid: comparison with other methods of purification. Hybridoma. 8:8595.

22. Laemmli, U. K. 1970. Cleavage of structural proteins during the assembly of the head of bacteriophage T4. Nature (Lond.). 227:680-685.

23. Rein, R. S., G. H. A. Seemann, J. J. Neefjes, F. M. H. Hochstenbach, N. J. Stam, and H. L. Ploegh. 1987. Association with $\beta_{2}$-microglobulin controls the expression of transfected human Class I genes. J. Immunol. 138:1178-1183.

24. Perarnau, B. M., A. C. Gillet, R. Hakem, M. Barad, and F. A. Lemonnier 1988. Human $\beta_{2}$-microglobulin specifically enhances cell-surface expression of HLA class I molecules in transfected murine cells. J. Immunol. 141:1383-1389.

25. Klar, D., and G. J. Hammerling. 1989. Induction of assembly of MHC class I heavy chains with $\beta_{2}$ microglobulin by interferon- $\gamma$. EMBO (Eur. Mol. Biol. Organ.) J. 8:475-481.

26. Sturmhofel, K., and G. J. Hammerling. 1990. Reconstitution of $\mathrm{H}-2$ class I expression by gene transfection decreases susceptibility to natural killer cells of an EL4 class I loss variant. Eur. J. Immunol. 20:171-177.

27. Storkus, W. J., D. N. Howell, R. D. Salter, J. R. Dawson, and P. Cresswell.
1987. NK susceptibility varies inversely with target cell class expression. J. Immunol. 138:1657-1659.

28. Algarra, I., C. Ohlen, M. Perez, H.-G. Ljunggren, G. Klein, F. Garrido, and K. Karre. 1989. NK sensitivity and lung clearance of MHC-class-I-deficient cells within a heterogeneous fibrosarcoma. Int. J. Cancer. 44:675-680.

29. Carlow, D. A., U. Payne, N. Hozumi, J. C. Roder, and A. A. Czitrom. 1990. Class I (H-2K $\left.\mathbf{K}^{\mathrm{b}}\right)$ gene transfection reduces susceptibility of YAC-1 lymphoma targets to natural killer cells. Eur. J. Immunol. 20:841-846.

30. Ohlen, C., M.-T. Bejarano, A. Gronberg, S. Torsteinsdottir, L. Franksson, H.-G. Ljunggren, E. Klein, G. Klein, and K. Karre. 1989. Studies of sublines selected for loss of HLA expression from an EBV-transformed lymphoblastoid cell line. Changes in sensitivity to cytotoxic $T$ cells activated by allostimulation and natural killer cells activated by IFN or IL-2. J. Immunol. 142:3336-3341.

31. Shimizu, Y., and R. DeMars. 1989. Demonstration by class I gene transfer that reduced susceptibility of human cells to natural killer cell-mediated lysis is inversely correlated with HLA class I antigen expression. Eur. J. Immunol. 19:447-451.

32. Ferrier, P., C. Layet, D. H. Caillol, B. R. Jordan, and F. A. Lemonnier. 1985. The association between murine $\beta 2$-microglobulin and HLA Class I heavy chains results in serologically detectable conformational changes of both chains. J. Immunol. 135:1281-1287.

33. Storkus, W. J., J. Alexander, J. A. Payne, P. Cresswell, and J. R. Dawson. 1989. The $\alpha 1 / \alpha 2$ domains of class I HLA molecules confer resistance to natural killing. J. Immunol. 143:3853-3857.

34. Jabrane-Ferrat, N., F. Calvo, A. Faille, J. F. Lagabrielle, N. Boisson, A. Quillet, and D. Fradelizi. 1990. Recombinant gamma interferon provokes resistance of human breast cancer cells to spontaneous and IL-2 activated non-MHC restricted cytotoxicity. Br. J. Cancer. 61:558-562.

35. Gorelik, E., Y. Gunji, and R. B. Herberman. 1988. H-2 antigen expression and sensitivity of BL6 melanoma cells to natural killer cell cytotoxicity. J. Im munol. 140:2096-2102.

36. Temponi, M., G. Romano, C. M. D'Urso, Z. Wang, U. Kekish, and S. Ferrone. 1988. Profile of intercellular adhesion molecule-1 (ICAM-1) synthesized by human melanoma cell lines. Semin. Oncol. 15:595-607.

37. Harel-Bellan, A., A. Quillet, C. Marchiol, R. DeMars, T. Tursz, and D. Fradelizi. 1986. Natural killer susceptibility of human cells may be regulated by genes in the HLA region on chromosome 6. Proc. Natl. Acad. Sci. USA. 83:56885692 .

38. Gronberg, A., R. Kiessling, and W. Fiers. 1985. Interferon- $\gamma$ is a strong modulator of NK susceptibility and expression of $\beta 2$-microglobulin but not of transferrin receptors of K562 cells. Cell. Immunol. 95:195-202.

39. Gronberg, A., M. T. Ferm, J. Ng, C. W. Reynolds, and J. R. Ortaldo. 1988 IFN- $\gamma$ treatment of K562 cells inhibits natural killer cell triggering and decrease the susceptibility to lysis by cytoplasmic granules from large granular lymphocytes. J. Immunol. 140:4397-4402.

40. Main, E. K., D. S. Monos, and L. A. Lampson. 1988. IFN-treated neuroblastoma cell lines remain resistant to $\mathrm{T}$ cell-mediated allo-killing, and susceptible to non-MHC-restricted cytotoxicity. J. Immunol. 141:2943-2950.

41. Quillet, A., F. Presse, C. Marchiol-Fournigault, A. Harel-Bellan, M. Benbunan, H. Ploegh, and D. Fradelizi. 1988. Increased resistance to non-MHC-restricted cytotoxicity related to HLA A, B expression. Direct demonstration using $\beta_{2}$-microglobulin-transfected Daudi cells. J. Immunol. 141:17-20.

42. Leiden, J. M., B. A. Karpinski, L. Gottschalk, and J. Kornbluth. 1989. Susceptibility to natural killer cell-mediated cytolysis is independent of the level of target cell class I HLA expression. J. Immunol. 142:2140-2147.

43. Stam, N. J., W. M. Kast, A. C. Voordouw, L. B. Pastoors, F. A. van der Hoeven, C. J. M. Melief, and H. L. Ploegh. 1989. Lack of correlation between levels of MHC class I antigen and susceptibility to lysis of small cellular lung carcinoma (SCLC) by natural killer cells. J. Immunol. 142:4113-4117.

44. Pena, J., C. Alonso, R. Solana, R. Serrano, J. Carracedo, and R. Ramirez. 1990. Natural killer susceptibility is independent of HLA class I antigen expression on cell lines obtained from human solid tumors. Eur. J. Immunol. 20:24452449.

45. Maziarz, R. T., S. J. Mentzer, S. J. Burakoff, and D. V. Faller. 1990. Distinct effect of interferon- $\gamma$ and MHC Class I surface antigen levels on resistance of the K562 tumor cell line to natural killer-mediated lysis. Cell. Immunol. 130:329-338.

46. Ljunggren, H.-G., K. Sturmhofel, E. Wolpert, G. J. Hammerling, and K. Karre. 1990. Transfection of $\beta_{2}$-microglobulin restores IFN-mediated protection from natural killer cell lysis in YAC-1 lymphoma variants. J. Immunol. 145:380386.

47. Tsai, L., C. Ohlen, H.-G. Ljunggren, K. Karre, M. Hansson, and R. Kiessling. 1989. Effect of IFN- $\gamma$ treatment and in vivo passage of murine tumor cell lines on their sensitivity to lymphokine-activated killer (LAK) cell lysis in vitro; association with H-2 expression on the target cells. Int. J. Cancer. 44:669-674. 